\title{
La ciudad en el Brasil: Por una nueva comprensión del fenómeno urbano brasileño
}

\author{
Paulo Roberto TEIXEIRA DE GODOY \\ Dpto. de Geografía. Universidad Estadual Paulista “Júlio de Mesquita Filho”. \\ prtg@rc.unesp.br \\ José GILBERTO DE SOUZA \\ Dpto. de Geografía. Universidad Estadual Paulista "Júlio de Mesquita Filho". \\ jgilbert@rc.unesp.br
}

Recibido: 20 de marzo de 2012

Enviado a evaluar: 21 de abril de 2012

Aceptado: 22 de marzo de 2013

\section{RESUMEN}

El artículo presenta el análisis del proceso de urbanización durante el periodo colonial y la importancia de la ciudad para la empresa de la conquista, colonización y formación del territorio brasileño. La ciudad como espacio de mediación de las relaciones de poder entre Metrópoli y Colonia y, al mismo tiempo, de control de la producción, del consumo y de la circulación de mercancías, constituye el punto de partida para replantearse la trayectoria del proceso de urbanización en Brasil, superando la perspectiva urbanoindustrial.

Palabras clave: Brasil, formación territorial, ciudad, colonización

\section{The city in Colonial Brazil: a new understanding of Brazilian urban phenomenon}

\begin{abstract}
The paper presents the analysis of the process of urbanization during the colonial period and the importance of the city to the enterprise of conquest, colonization and formation of the Brazilian territory. The city as a mediation of power relations between Metropolis and Cologne and at the same time, control of production, consumption and circulation of goods, is the starting point for rethinking the trajectory of urbanization in Brazil, surpassing urban-industrial perspective.
\end{abstract}

Key words: Brazil, territorial formation, city, colonization

\section{La ville coloniale Brésil: une nouvelle compréhension de phénomène ur- bain brésilien}

\section{RÉSUMÉ}

Cet article présente l'analyse du processus d'urbanisation au cours de la période coloniale et l'importance de la ville à l'entreprise de conquête, de la colonisation et de la formation du territoire brésilien. La ville comme la médiation des relations de pouvoir entre Metropolis et Cologne et dans le même temps, le contrôle de la production, la consommation et la circulation des marchandises, est le point de départ pour repenser la trajectoire de l'urbanisation dans Brésil, dépassant perspective urbaine et industrielle.

Mots clés: Brésil, formation territoriale, ville, la colonisation 


\section{INTRODUCCIÓN}

Iniciada en los primeros siglos de la colonización, la urbanización en Brasil constituye un proceso histórico y espacial en curso. Acompañó de manera singular la formación del territorio colonial y, posteriormente, la del territorio nacional. Con una configuración litoral, la urbanización se integró en las prácticas económicas y geopolíticas de dominio territorial en el interior del país. La acción urbanizadora del sistema colonial portugués confirió a lo que más tarde sería Brasil, un carácter urbano antes que rural (REIS FILHO, 1968; OLIVEIRA, 1982).

Conocer lo urbano en su fase actual exige, por tanto, comprenderlo en el pasado. No como objeto capturado y separado del presente - una vez que el concepto de historia no se desarrolla solamente en el pasado - sino como espacio social construido en momentos históricos distintos. El sentido de la investigación sobre lo urbano en Brasil entre los siglos XVI y XVIII, se centra en el interés de traer al campo del análisis de la producción capitalista del espacio urbano elementos de naturaleza geopolítica y económica que contribuyan al esfuerzo de reconceptuación de lo urbano en Brasil y al conocimiento necesario del proceso histórico de las relaciones entre poder y territorio en la producción del espacio geográfico nacional.

El análisis histórico y geográfico del proceso de urbanización debe priorizar, con todo, una compresión más amplia del origen de la ciudad en Brasil y de su papel en la organización del territorio. La caracterización del proceso de urbanización y de sus particularidades pone en evidencia la importancia que tiene, para la geografía y especialmente para la geografía urbana, los orígenes y significados de la ciudad en el proceso de colonización y formación territorial.

Los estudios realizados durante las décadas de 1940 y 1950 y los avances en términos de análisis teórico sobre la ciudad en Brasil, imprimieron una imagen y una definición de cuño funcional y dualista que, insistentemente, se mantiene en la base de las actuales versiones sobre la ciudad (la ciudad sirve para alguna cosa, sirve a alguna cosa). El énfasis gravita, sobremanera, en torno a las formas y las funciones y valora el dato en detrimento de la formación socio-espacial en su devenir histórico y, muchas veces, reposa sobre un anacronismo que condiciona el concepto de ciudad a una única temporalidad - la del presente - y sanciona las conexiones espaciales a la historicidad de los objetos que componen el paisaje urbano. El concepto de ciudad está ligado, en este sentido, exclusivamente a los flujos de mercancías y a las necesidades del comercio y de la concentración de excedentes (mano de obra y producción agrícola). La ciudad desempeña una función de soporte de las necesidades de la producción y del consumo; incluso siendo, ella misma, objeto central de producción y consumo.

Un ejemplo de este desdoblamiento conceptual puede percibirse en el estudio realizado por B. BECKER (1987, p. 111), sobre el origen del fenómeno urbano en la frontera de recursos de la Amazonia brasileña, cuya hipótesis básica es que las ciudades en aquella frontera suregieron por la "movilización, extracción y concentración geográfica de cantidades significativas del producto excedente socialmente designado". 
Inspirada por la obra de D. HARVEY (1980) La Justicia Social y la Ciudad, BECKER (1978/1987) intenta explicar la ciudad como un espacio "designado" al mercado de trabajo, a la concentración del excedente agrícola y a los servicios básicos para atender las necesidades de la población.

En los años 90, BECKER (1990) argumentó que en la Amazonia la ciudad no aparece como consecuencia directa de la expansión agrícola, sino de la propia urbanización. Las funciones de las ciudades son básicamente las de atracción poblacional, formación del mercado de trabajo y control social.

Esos elementos formadores de la ciudad, cuando no son evaluados aisladamente, son concebidos como fenómenos del proceso de desarrollo económico y de expansión territorial de la agricultura. Mientras, el hecho de que la ciudad no sea sólo el resultado de lo económico (división espacial del trabajo) o de lo político, sino también de la técnica y de la cultura, hace que Becker la defina a partir del producto agrícola excedente y de la concentración de la mano de obra, sin considerar a los agentes y los procesos que forjaron la urbanización y los mecanismos económicos de concentración de la producción y de la mano de obra.

El análisis marxista del espacio urbano, sobre todo de cuño lefebvreano, realizó importantes contribuciones al estudio del binomio urbanización-industrialización. Sin embargo, la cuestión urbana no puede sustentarse en la lógica eurocéntrica y del determinismo evolucionista de las fuerzas de producción, sin considerar las diferentes condiciones de intercambio orgánico entre hombre y naturaleza que se produjeron en la formación territorial brasileña de carácter esencialmente agrícola, presuponiendo el mismo tratamiento teórico y conceptual que para las ciudades industriales europeas, de donde se abstrajeron todas las características urbanas.

Este hecho no habla, efectivamente, en contra del análisis y la forma de comprensión de los objetos (la ciudad, lo urbano, por ejemplo), pero el proceso histórico de la urbanización, sobre todo en los primeros siglos de colonización en Brasil, expone el desdoblamiento de la fragilidad conceptual que marca la deficiencia teórica de la geografía urbanística brasileña hasta nuestros días. Un proceso que se establece por no reconocer la especificidad óntica del objeto-fenómeno y determinar una subjetividad científica sobre una objetividad histórico-concreta de la urbanización y de la formación territorial brasileñas.

Las consideraciones generales que se presentarán, permiten reevaluar los diferentes abordajes sobre lo urbano y, sin duda, sus limitaciones cuando se analizan en el contexto histórico y espacial de su génesis y desarrollo.

La idea central de este pequeño artículo procura centrarse en la creación del espacio urbano en los primeros siglos de colonización y presentar las posibilidades de realizar una reflexión sobre el actual concepto de lo urbano, su onticidad y su significado teórico-metodológico en geografía. 


\section{CONSIDERACIONES SOBRE LO URBANO EN BRASIL}

La ciudad siempre estuvo presente en la historia de las diferentes sociedades. En culturas de base agrícola o comercial, se presentó como una mediación entre las mediaciones (LEFEBVRE, 1991). Como escenario de la evolución social, la ciudad se convirtió en sede del poder político y, al mismo tiempo, de la producción y del consumo o aún, como quiere LA BLACHE (1955), en una "fábrica de culturas".

En La Géographie Humaine, J. BRUNHES (1934) aseveró que la ciudad no pasa de una aglomeración improductiva y que puede analizarse como una especie de "ser natural". En la acepción de M. SORRE (1953, p. 256), la ciudad en su forma específica, "es un lugar de contactos y de intercambios de actividades, formas de vida, sistemas de necesidades distintas". Para este autor, "las ciudades traducen, en su estructura interna y en su fisionomía, el carácter dominante de la civilización que las origina". Afirmó también que en el origen de las ciudades está la acción consciente y que "el contacto de dos regiones sería propicio para el nacimiento de ciudades y una gran carretera, con sus hitos, determinaría verdaderas líneas urbanas". Según el autor:

Existe una ciudad cuando hay coalescencia de funciones en una aglomeración. Esta expresión significa que las funciones llegan a depender unas de otras, volviéndose así independientes de la actividad primaria que dio origen a la aglomeración (SORRE, 1953, p. 257)

Para MUNFORD (1961, p. 16 y 494), la ciudad representó la "humanización del ambiente natural" y constituyó un "complejo geográfico, una organización económica, un proceso institucional, un teatro de acción social y un símbolo estético de unidad colectiva". La ciudad condensó en su materialidad, la técnica, el arte y las funciones sociales, haciendo del urbanismo y de la política urbana instrumentos inseparables de la producción del espacio urbano.

Para F. BRAUDEL (1967), en Civilsation matérelle, économie et capitalisme, la ciudad se constituyó como un producto de la división social del trabajo y, al mismo tiempo, condición concreta de existencia de los mercados nacionales.

El espacio urbano, en la conjugación de las concepciones arriba expuestas, consistía en un lugar de mediaciones, de posibilidades, de intercambios y de formas de vida. En la historia de las conquistas territoriales, las ciudades fueron organizadas como espacios del poder político y militar, de consumación del proceso colonizador y de ordenación de los flujos de mercancías.

Inicialmente se debe destacar que la colonización portuguesa en Brasil, a partir del siglo XVI, mostró que el desempeño de las ciudades en el dominio territorial fue de suma importancia para el éxito de la empresa colonizadora. La fundación de villas, parroquias y aldeas se reveló, muchas veces, como una técnica de apropiación territorial. El papel específico de la ciudad se ligaba a un aspecto intencional de demarcación de fronteras y garantizó el dominio sobre las tierras conquistadas. La supervivencia de esas ciudades dependió menos del campo que de la geopolítica administrativa llevada a cabo por la Corona. Esta, sin duda, constituyó una perspectiva promisora de interpretación de lo urbano en la colonia y, ciertamente, la geografía 
podría arrojar luz sobre el pasado de las ciudades brasileñas y reconstruir la trayectoria histórica y espacial del proceso de urbanización-formación territorial.

\section{LA CIUDAD EN LA COLONIA}

En Brasil, la expansión de la colonización portuguesa trajo, inevitablemente, la existencia de parroquias, patrimonios, ciudades, villas y aldeas. La presencia de esos núcleos urbanos en el paisaje reflejaba y caracterizaba las preocupaciones políticoadministrativas de la Metrópoli en relación a la ocupación y explotación del territorio que poco a poco dibujaba una nueva cartografía de los límites de los dominios de la Corona Portuguesa.

La idea de crear ciudades en el proceso de colonización de nuevas áreas es una práctica secular. Las fronteras económicas, según BUARQUE DE HOLANDA (1963, p. 61-62), "establecidas en el tiempo y en el espacio por las fundaciones de ciudades (...) se convirtieron también en las fronteras del mundo que más tarde ostentaría la herencia de la cultura clásica".

En América Latina, la colonización portuguesa y española a partir del siglo XVI, ocupó y demarcó sus territorios mediante la creación de ciudades y desarrolló una base económica que necesariamente pasaba por ellas.

Para GEIGER (1963, p. 69),

Las localidades fundadas en Brasil pueden no haber tenido, durante decenas de años, gran expansión desde el punto de vista de su población (...) Salvador, por ejemplo, precede a la expansión azucarera en el Recôncavo Baiano y lo mismo se puede afirmar respecto a Río de Janeiro y el Recôncavo da Gunabara. Fue apoyándose en estas ciudades como, inicialmente, se desarrollaron los ingenios de azúcar en los alrededores.

En el siglo XVI, como destacó REIS FILHO (1968, p. 66), Portugal ya ponía en práctica una política urbanizadora en Brasil, como "solución más eficaz de colonización y dominio". El espacio urbano como lugar de concentración de bienes y personas, control político, militar y religioso, así como de difusión del poder instituido, se integró de modo singular en la práctica de la conquista territorial.

La política urbanizadora no se dirigió evidentemente a la creación de una economía urbana y con base regional de influencias directas sobre un determinado hinterland. Antes que estimular, la política urbana portuguesa se concentró en detener el crecimiento urbano en las colonias. Los núcleos urbanos fundados en el periodo colonial se caracterizaban a penas en sentido político de dominio territorial y control fiscal sobre la producción y la circulación de mercancías.

En la acepción de HOLANDA (1963, p.66), "los portugueses ponían todas las dificultades a las incursiones tierra adentro, recelosos de que eso despoblase la costa". Ya el primer gobierno general de Brasil tomó medidas respecto a la contención de lo 
urbano en la orla costera con impedimentos para su interiorización porque por dentro de la tierra firme por el sertón no podrán hacer más (...) villas, sin licencia previa de Su Majestad (HOLANDA, 1963, p. 66). La fundación de aldeas y su elevación a la categoría de villas pasó a ser considerada como título de benemerencia de los gobernadores coloniales ante la Corona portuguesa.

En otro sentido, la política urbanizadora de la Metrópoli visaba, sobre todo, mantener el control "más directamente sobre la fundación y el desarrollo de las ciudades y estimular, indirectamente, la acción urbanizadora de sus donatarios" (REIS FILHO, 1968, p. 84).

El periodo de conquista territorial que se extendió entre el final del siglo XVI hasta mediados del siglo XVII (periodo de dominación española, 1580-1640), presentó las primeras trazas de lo que constituiría la política urbanizadora de la Metrópoli portuguesa.

La conquista de nuevos territorios a partir de ciudades empezó en Paraíba (1585), Natal (1599) y São Luis de Maranhão (1612); y con la fundación de aldeas en el interior como Caeté (1634), Canutá (1635), Alcântara (1637) y Gurupá (1639), en los actuales Estados de Maranhão y Pará.

A medida que la ciudad volvía la acción colonizadora más eficaz y aseguraba un relativo control sobre los diferentes usos del territorio, hizo que su participación en la economía fuese cada vez más amplia y su papel político cada vez más incisivo sobre la vida colonial.

Es importante resaltar el papel desempeñado por la Iglesia en la fundación de villas y ciudades. La oficialización de núcleos urbanos ante el poder institucional se producía con la edificación de una capilla que una vez visitada por un cura era promovida a la categoría de villa o ciudad. No obstante, según M. MARX (1991, p. 19),

No bastaba, con todo, erguir una ermita; no bastaba construir, por mejor que fuese, una capillita; era necesario oficializarlas. No era suficiente dotar a la aldea de un abrigo para el ejercicio religioso en común; era necesario consagrarlo.

El espacio urbano pasó a representar no solamente el poder del Estado, mediante la aplicación de normas y códigos de fundación y regulación de la parcelación del suelo, sino también el de la Iglesia católica, para la difusión cultural-ideológica y la catequización.

La influencia ejercida por la organización de esas relaciones de poder entre Estado e Iglesia sobre lo urbano representó, de acuerdo con M. MARX (1991), un factor decisivo en la definición de la red urbana brasileña. Este aspecto es comúnmente olvidado tanto por historiadores como por geógrafos urbanos.

La ciudad, en cuanto locus de decisión se convirtió en "pieza" fundamental de la empresa colonizadora y religiosa. Su expansión territorial implicó una mayor capacidad de control sobre la explotación de los recursos naturales y humanos y, de modo general, sobre la vida en la colonia. 
En el territorio paulista, por ejemplo, en las antiguas provincias de São Vicente y Santo Amaro, se fundaron entre 1610 y 1693 innumerables villas: Mogi das Cruzes (1611); Santana de Parnaíba (1625); Taubaté (1645); Jundiaí (1655); Itu (1657); Sorocaba (1661); e Iguape (1693) y en el oeste de Paraná estaba el núcleo de Guaíra, que fue destruido en 1627 , durante el conflicto entre jesuitas y bandeirantes ${ }^{1}$. De acuerdo con IANNI (1988, p. 56):

A principios del siglo XVII, la fundación de aldeas en el interior paulista proporciona apoyo y unión "a la basta red de ríos, senderos y caminos (o sitios, arrabales, parroquias, aldeas, villas y ciudades) que se crearon con la expansión del poblamiento en el planalto paulista, las regiones de Minas Gerais, Mato Grosso, Paraná y todo el sur del país”.

AZEVEDO (1957, p.151) argumentó que "los caminos coloniales constituyeron la espina dorsal de la red urbana brasileña". A principios del siglo XVIII, Brasil contaba con una red urbana de sesenta y cinco villas y ocho ciudades. Se fundaron en este periodo 118 villas en el Estado de São Paulo. Las principales son: Pindamonhangaba (1705); São José dos Campos (1967); Mogi Mirim (1769); Lorena (1788); Campinas (1797) y Bragrança Paulista (1797). En el mismo periodo, en el Centro-Oeste brasileño, surgieron Cuiaba (1727), Vila Bela (1752), Cáceres (1778) y Poconé (1780). Se debe ponderar que el número de ciudades y villas mencionado corresponde a los datos oficiales, o sea, exclusivamente los oficializados y sacramentados.

La distribución espacial de la red urbana y de su estructura interna revelan, en primer lugar, el sentido explotador de la colonización y la posición política de la Metrópoli portuguesa en relación a la Colonia; en segundo lugar, la influencia de la iglesia en el diseño de la ciudad a partir de la definición de su centralidad y de sus funciones culturales.

El control del Estado y de la Iglesia en la fundación y expansión de los núcleos urbanos orientados a la organización de la circulación de mercancías $\mathrm{y}$, al mismo tiempo, la voracidad que caracterizó la explotación de los recursos naturales de la colonia, incidió directamente en la ordenación del espacio interno de las ciudades.

En relación a la estructura interna de las ciudades, HOLANDA (1963, p. 62) argumentó, realizando una comparación entre la colonización española y portuguesa en América Latina que "el propio trazado de los centros urbanos en la América Española denuncia el esfuerzo decidido a vencer y rectificar la fantasía caprichosa del paisaje agreste". De acuerdo con AYMORD (1985, p. 138), sería una especie de "victoria del orden sobre la sombra, una ciudad ideal establecida bajo el signo del espíritu".

\footnotetext{
${ }^{1}$ Los bandeirantes eran los hombres que a partir del siglo XVI se adentraban en los territorios interiores de Brasil, partiendo de San Pablo de Piratininga (São Paulo). El nombre "bandeirante" proviene de la palabra portuguesa "bandeira" (bandera) ya que se agrupaban usando banderas que los distinguían. N. de la T.
} 
Sin considerar las implicaciones teóricas y las diferencias geográficas existentes entre las regiones Andinas y las del litoral brasileño, HOLANDA (1963) enfatizó el rigor geométrico de la ordenación del espacio urbano que "inmuniza" a las ciudades contra las fuerzas y las asimetrías de la naturaleza.

HOLANDA (1963, p. 62) caracterizó a la urbe de la colonización portuguesa como un espacio desorganizado e irracional, es decir, "no es un producto mental, no llega a contradecir el marco de la naturaleza, y su silueta sigue la línea del paisaje". En cuanto al trazado de las ciudades, el padre Antonio Vieira decía: no hace Dios el Cielo en cuadrícula de estrellas.

La villa de São Paulo, según XAVIER PEREIRA (1988, p. 82), consistía en un caserío estrecho en lo alto de la colonia, entrecruzada por los ríos Anhagabaú y Tamanduateí, que se mezclaba con las huertas y la cría de animales de los arrabales. En la descripción de AZEVEDO (1957, p. 152), São Paulo se presentaba "con sus tortuosas calles serpenteando en la cima de la colina, estrechas en un punto, anchas en otro, flanqueadas por casas bajas y enormes aleros de tejado que protegen las paredes de tapial". En palabras de MORGADO DE MATEUS, una verdadera ciudad de barro.

El espacio interno de las ciudades coloniales en Brasil traducía, en primer lugar, el objetivo de la empresa colonizadora y, consecuentemente, la función que se le atribuyó en el proceso de explotación del territorio. Además de eso, se debe añadir como informó AZEVEDO (1957, p. 152), que los núcleos urbanos creados por las autoridades coloniales

obedecían, en sus orígenes, un plano regular y geométrico, si bien adaptado a las características topográficas. Pronto, no obstante, se dejaba de lado esa preocupación urbanística y la expansión pasaba a realizarse de manera más espontánea.

Además la localización del sitio urbano no se producía de manera aleatoria, sino obedeciendo a una legislación específica creada por el Estado y por la Iglesia. Así, según el

derecho canónico, las Iglesias se deben fundar, y edificar, en lugares decentes, y acomodados, por lo que mandamos, que habiendo que edificar de nuevo alguna iglesia parroquial en nuestro Arzobispado, se edifique en sitio alto, y lugar decente, libre de humedad, y alejado, cuanto fuera posible, de lugares inmundos (M. MARX, 1991, p. 22)

En la concepción de HOLANDA (1963), los núcleos urbanos se caracterizaban por la pequeña concentración de casas en torno a una iglesia, generalmente localizada en lo alto de un espigón. Ante la rebelión de la naturaleza, el trazado de las calles, de las manzanas o de la plaza central se hacía a medida que se construían las casas, los edificios públicos y la iglesia. La costumbre de destacar a la iglesia dentro del paisaje era una tradición y una decisión política, estética y simbólica que, en realidad, obe- 
decía según M. MARX (1991, p. 23) a una legislación clara que debía cumplirse si había pretensión de consagración.

De ese modo, la configuración topográfica del sitio urbano, se constituye en otro obstáculo para la geometrización del espacio interno de las ciudades. Los casos de Salvador, São Vicente, Ouro Preto y otros, son ejemplos de "obediencia" de la estructura urbana a las sinuosidades del terreno.

El trazado previo, que procuraba organizar la ocupación del suelo urbano surgió históricamente como respuesta a los cambios en las funciones adquiridas por la ciudad en la economía colonial y por la valorización del suelo urbano derivada del crecimiento y de la concentración poblacional.

Aunque la Iglesia, junto al Estado, haya sido responsable en gran parte de la expansión urbana, su distribución espacial a lo largo del litoral correspondía a los objetivos económicos y geopolíticos de la Corona portuguesa. La localización de las ciudades y el trazado de los caminos que las ligaban, se relacionaban directamente con las necesidades de producción, extracción y circulación de mercancías.

En relación a la configuración litoral de la urbanización, OLIVEIRA (1982, p. 37) argumenta que "las ciudades se constituyeron según un patrón litoral no sólo debido a su carácter exportador de productos primarios, sino también debido a la división social del trabajo". El espacio urbano era, al mismo tiempo, la sede del Estado portugués en tierras coloniales y el punto de conexión con la circulación internacional de mercancías.

Para REIS FILHO (1968, p. 38), la ciudad se estableció como resultado del proceso de urbanización y no al contrario. Y es que según Oliveira,

Estamos acostumbrados a entender que el fenómeno de la urbanización en la sociedad y en la economía brasileña estalla sólo a partir de la industrialización (...) lo que nos ha llevado a despreciar, de cierta forma, la formación urbana dentro de las condiciones de la economía exportadora (OLIVEIRA, 1982, p. $38)$.

En perspectiva inversa, LENCIONE afirmó que (2008, p. 121),

Sería un grosero error expresar que lo urbano se relaciona con la sociedad capitalista industrial y, al mismo tiempo, discutir lo urbano en el siglo XVIII al hablar de las ciudades mineras: Ouro Preto, Mariana y Sabará, por ejemplo. Como también sería falta grave hablar de urbano en Brasil a finales del siglo XIX si la comprensión de lo urbano se apoya en la idea de sociedad capitalista industrial entendida como aquella cuyo fundamento de la reproducción ampliada del capital se encuentra en la actividad industrial. 
Se incurre aquí en una confusión entre el tiempo teórico y el tiempo histórico del capitalismo. El tiempo teórico se refiere al "contenido material de la riqueza", que se establece por el trabajo, cuya forma particular en el capitalismo se realiza en la plusvalía (MARX, 1983, p. 46). El tiempo histórico se refiere a uno de los estados de esa forma, que se realiza de manera profunda en la explotación de la plusvalía, marcada por la alteración de la composición técnica y orgánica del capital: el proceso de industrialización.

La ciudad se convierte, así, en territorio fértil para su consecución. En realidad las ciudades industriales dejan de ser el espacio de la reproducción del capital por la lógica de la explotación del trabajo abstracto improductivo, donde se realizan funciones para obtener la plusvalía (comercio y control de la producción), para ser el espacio del trabajo abstracto productivo, efectivamente la actividad de intercambio orgánico con la naturaleza, en la producción de mercancías, que hasta entonces se restringía, o hegemónicamente se constituía en lo rural (MARX, 1983).

Esa fragmentación de la trayectoria de la urbanización insertada por la funciónactividad (industria), oscurece la permanencia de la condición material de explotación que el capitalismo ejerció sobre lo rural, y en el caso del Brasil colonia mediado por lo urbano.

La red urbana brasileña, cuya génesis está en los primeros siglos de colonización, se constituyó como un conjunto de respuestas a las solicitudes del proceso de conquista territorial y de ampliación de las relaciones capitalistas de producción. De esa forma, concebir lo urbano solamente a partir del proceso de industrialización podría restringirlo a su materialidad y a los aspectos relacionados con la centralidad urbana y las relaciones ciudad-campo y, por otro lado, acortar las estrategias de ocupación territorial y las funciones políticas que desempeñó la ciudad en la economía colonial.

Se considera que el movimiento de acumulación primitiva del capitalismo mercantil tuvo su sede de control en la ciudad porque se trataba de una economía con una función específica dentro del sistema internacional de acumulación. Organizado y creado para atender a la economía de exportación, el espacio urbano surge en Brasil antes incluso que el campo. "Lo urbano en Brasil está históricamente fundado en una contradicción singular: mientras que el locus de la producción era rural, agrario, el locus del control fue urbano" (OLIVEIRA, 1982, p. 38).

La política de explotación de recursos llevada a cabo por la Corona portuguesa en Brasil, no excluye la idea de fundación de ciudades como forma de dominio territorial y puntos de distribución de mercancías. La articulación entre ellas condicionó la red urbana y el modo en el que se desarrolló el proceso de colonización.

Vale mencionar de pasada que la colonización portuguesa en Brasil no se caracterizó por ser un movimiento demográfico. En realidad, como argumenta NOVAES (1997, p. 20), "la colonización moderna no fue un fenómeno esencialmente demográfico (...) en el sentido de que no fue impulsado por presiones demográficas". La colonización a partir del siglo XVI se vinculó más directamente a los procesos de formación de los Estados Nacionales y a la expansión comercial. En el plano político, se produjo un permanente esfuerzo metropolitano por expandir el territorio de la dominación colonial más allá de la capacidad de explotación económica. 
La ruptura de la concentración del poblamiento en la franja costera, se produjo parcial y momentáneamente en la fase de la minería, de la mano de un importante movimiento migratorio hacia a las regiones de Minas Gerais y el sur de Goiás. Según DEFFONTAINES (1944, p. 143), "la colonización minera se presentó esencialmente en la forma de una civilización urbana".

La vida urbana en la colonia fue concebida como una prolongación y un complemento de la Metrópoli y, al mismo tiempo, como su negación y su reverso. La población de la colonia, desde la perspectiva metropolitana, era equivalente a la de la Metrópoli, pero la Metrópoli se posicionaba como región de emigración y la colonia como zona de inmigración (NOVAES, 1997).

La fuerte concentración económica y política en São Paulo y Río de Janeiro a partir de mediados del siglo XIX, asociada a las formas de control sobre la distribución de tierras, se constituyeron en factores internos que contribuyeron al fortalecimiento de la economía litoral. Para AZEVEDO (1957, p. 114), "la obra de urbanización consiguió liberarse de la orla atlántica, como resultado de la expansión pobladora y de la conquista del Planalto Brasileño y de la propia Amazonia".

NOVAES (1997, p. 25) defiende que la economía agro-exportadora se organiza hacia fuera y adquiere mayor estabilidad de ocupación; la economía de subsistencia (como la de São Paulo, o la ganadera del Nordeste), está orientada hacia adentro y, paradójicamente, se presenta más inestable y con mayor movilidad espacial.

Como hilo de unión entre Metrópoli y Colonia, la ciudad se encontraba envuelta en un conjunto de relaciones político-administrativas, comerciales y culturales que la convertían, cada vez más, en parte de una red urbana y de un sistema económico interno.

La política urbanizadora, como sostuvo REIS FILHO (1968), tiene sus desdoblamientos durante todo el siglo XVIII para consolidarse como proceso de urbanización en el siglo XIX, cuando el espacio urbano adquiere nuevos significados para los agentes sociales, políticos y económicos de la conquista territorial. Desde la perspectiva del poder de la Metrópoli portuguesa, los núcleos urbanos de la colonia se convirtieron en espacios de control y, al mismo tiempo, ampliaron con eficacia el sistema administrativo. Para el Estado brasileño, la ciudad se convertirá en la condición concreta de intervención política y económica en la sociedad.

Las mejoras en los cuadros administrativos a principios del siglo XIX implicaron la incorporación de nuevos servicios típicamente urbanos (jurídico-burocráticos, comerciales, transportes y culturales) y provocó la alteración de las funciones de la ciudad, así como cambios importantes en la regulación del uso del suelo urbano. Las demandas de servicios derivadas de las actividades agrícolas y comerciales pasaron a ser atendidas en el ámbito de la ciudad, dando lugar a la edificación de edificios públicos, establecimientos comerciales, casas teatrales, escuelas, bibliotecas públicas, plazas, etc.

Con la densificación de la aglomeración urbana, aumentó la presión sobre el uso del suelo y, por ende, las necesidades de parcelación y geometrización del espacio 
interno de las ciudades. La parcelación del suelo urbano como forma de reglamentación y control del uso y ocupación, inició la elaboración de reglas y normas impuestas exclusivamente para las ciudades. La división de los lotes implicó, entre otros aspectos, la definición de espacios públicos y privados, así como la definición de su valor.

Según GEIGER (1963), tres factores contribuyeron a la expansión urbana durante el siglo XIX: la abolición de la esclavitud, la mayor división del trabajo y el desarrollo de las medias y pequeñas propiedades rurales. Un cuarto factor que se puede mencionar es la inmigración europea en las últimas décadas del siglo XIX, sobre todo, hacia São Paulo y los Estados del sur de Brasil. Por otro lado, observó DEFFONTAINES (1994, p. 144), "en el transcurso del siglo XIX, con el declive de la minería, la montaña quedó vacía, con sus ciudades muertas, verdaderos monumentos históricos perdidos en un desierto: São João Del Rei, Congohas do Campo".

Según SANTOS (1996, p. 20), "al final del periodo colonial, las ciudades, entre ellas São Luis do Maranhão, Recife, Salvador, Río de Janeiro y São Paulo, sumaban cerca del $5,7 \%$ de la población total del País, donde vivían, entonces, 2.850.000 habitantes".

La historia de la colonización portuguesa en Brasil muestra también la historia y la geografía de la ciudad. De la conquista territorial a la exportación de productos agrícolas, la ciudad desempeñó un papel fundamental en el mapa económico y político del Estado Portugués, constituyéndose, al mismo tiempo, como espacio de control y poder sobre el territorio y punto de articulación con la economía metropolitana, haciéndose mundial antes incluso que nacional.

Las relaciones económicas entre Metrópoli y Colonia, mediadas por la ciudad, dependían menos del éxito de la empresa de la colonización que de lo relativo a la política administrativa establecida por la Metrópoli. La singularidad de la red urbana brasileña deriva, en gran parte, de este aspecto, en cuanto espacio de articulación interna y mediación externa entre Colonia y Metrópoli.

La cuestión urbana en el Brasil colonial puede parecer, en una primera aproximación, extraña a los geógrafos, pero no siempre fue así. Durante las décadas de 1940 y 1950, geógrafos como P. Deffontaines (1944), P. Monbeig (1952), Aroldo de Azevedo (1956) y a principios de los años 60, Pedro Geiger (1963), desarrollaron estudios importantes sobre la urbanización y la formación de la red urbana, destacando la relevancia y las especificidades de lo urbano en el periodo colonial.

A partir de la década de 1960, la red urbana, la urbanización e industrialización, la regionalización y la planificación regional constituyeron tendencias dentro de la geografía que definitivamente rompieron con los temas urbanos relativos a las fases pretéritas de la historia de la urbanización brasileña.

Lo apuntado arriba sólo pretende mostrar la complejidad de la urbanización brasileña y la necesidad de reconstruir su historicidad a partir de la perspectiva espacial. La Geografía y, en particular, la geografía urbana, han cambiado constantemente la temática de sus estudios excesivamente especializados, muchas veces, hasta el punto de despojar al propio concepto de urbano de su naturaleza geográfica e histórica. 
La reconstitución de las temporalidades del proceso de urbanización desde la perspectiva geográfica rectifica las definiciones del presente $\mathrm{y}$, en escalas espaciales sucesiva, explicita las determinaciones en el contexto de diferentes periodos. Los anacronismos históricos que caracterizan las diversas periodizaciones existentes sobre el proceso de urbanización son aquellos que manipulan la continuidad temporal mediante un determinado orden arbitrario de hechos. No cabe, en este momento, discutir sobre los fundamentos teóricos que sustenta tales periodizaciones, pero vale destacar su escasa importancia para la lectura de la continuidad y discontinuidad del proceso de urbanización, además del aspecto político-ideológico que caracteriza la relación de poder con el pasado.

En suma, la cuestión urbana en el Brasil colonial y el problema de la periodización del proceso de urbanización remiten a un conjunto de problemas de naturaleza teórica y metodológica que lleva a la investigación no sólo hacia los aspectos relativos a la aparición y crecimiento de las ciudades, sino también a aquellos que redefinen las temporalidades $\mathrm{y}$, por tanto, los criterios de periodización del proceso de urbanización en Brasil.

\section{REFERENCIAS BIBLIOGRÁFICAS}

AYMORD, M. (1988) Espaços. In: Braudel, F. O Espaço e a História no Mediterrâneo. Tradução: M. Appenzeller. São Paulo: Martins Fontes, p.129-151.

AZEVEDO, Aroldo de. (1957) Vilas e cidades do Brasil Colonial: ensaio de geografia urbana retrospectiva. Anais da Associação dos Geógrafos Brasileiros, Tomo I (09), 1954-55, São Paulo: Associação dos Geógrafos Brasileiros, p. 147-162.

BECKER, B. H. (1978) Uma Hipótese sobre a origem do Fenômeno Urbano numa Fronteira de Recursos do Brasil. Rio de Janeiro: Revista Brasileira de Geografia, ano 40, n. 1, FIBGE, p. 98-115.

BRAUDEL, F. (1967) Civilization matérelle économie et capitalisme. Paris: Libraire Colin, 323p.

BRUNHES, J. (1934) La Géographie Humaine. Paris: Libraire Félix Alcan, 287p.

DEFFONTAINES, P. (1944) Como se Constituiu no Brasil a Rêde de Cidades. Rio de Janeiro: Boletim Geográfico, v. 2 (14), p. 139-151.

GEIGER, Pedro P. (1963) Evolução da Rede Urbana Brasileira. Rio de Janeiro: Instituto Nacional de Estudos Pedagógicos - Ministério da Educação e Cultura, $347 \mathrm{p}$.

HOLANDA, S. B. de. (1963) Raízes do Brasil. Brasília: UnB, 457p.

IANNI, O. (1988) Uma Cidade Antiga. Campinas: Unicamp, 267p.

LA BLACHE, P. V. de (1955) Principes de Geographie Humaine. Paris: Armand Colin, 480p.

LEFEBVRE, H. (1991) The Production of Space. Tradução: (translated): Donald N. Smith. Blackwell Publishing (USA), 530p.

LENCIONI, S. (2008) Observações sobre o conceito de cidade e urbano. Geousp espaço e tempo, São Paulo, n. 24, p. 109-123. 
MUNFORD, Lewis. (1961) A Cultura das Cidades. Tradução: Neil R. da Silva. Belo Horizonte: Editora Itatiaia Limitada, 425p.

MARX, M. (1991) Cidade no Brasil: terra de quem? São Paulo: Edusp/Nobel, 458p.

MARX, K. (1984) O Capital - V. I. São Paulo: Nova Cultural, 390p.

MONBEIG, P. (1943) O Estudo Geográfico das Cidades. Rio de Janeiro: Boletim Geográfico, v. 1, n. 7, p. 09-13.

NOVAIS, F. A. (1997) Condições da privacidade na colônia. In: História da Vida Privada : cotidiano na América Portuguesa (org.) Laura de Mello e Souza, São Paulo, Cia. Das Letras, p. 13-40.

OLIVEIRA, Francisco de. (1982) O Estado e o Urbano no Brasil. São Paulo: Espaço \& Debates, n.06, p. 27-41.

PEREIRA, Paulo C. Xavier. (1988) Espaço, técnica e construção. São Paulo: Nobel, $230 \mathrm{p}$.

SANTOS, M. A (1996) Urbanização Brasileira, São Paulo, Nobel, 370p.

SORRE, M. (1953) Les Fondements de la Géographie Humaine (tomo III). Paris: Libraire Félix Alcan, 489p. 